\title{
Immunogenicity Specimen Assessments Numeric Result in Standard Unit
}

National Cancer Institute

\section{Source}

National Cancer Institute. Immunogenicity Specimen Assessments Numeric Result in

Standard Unit. NCI Thesaurus. Code C117562.

The numerical identifier of an immunog enicity specimen assessment result in standard units. 